\title{
TEMPORAL REGISTRATION OF RADIOFREQUENCY INFORMATION AND CT IMAGES FOR RADIOFREQUENCY ABLATION PROCEDURE
}

Type: Article

Abstract:

A computed tomography (CT) scanner is often used for visualization during the radiofrequency (RF) ablation (RFA) procedure. Temperatures at the ablation zone, power output, efficiency, and annotation are recorded once per second in the RF generator. Radiologists often review the RF and CT data post-operation for diagnostic and research purposes. However, they often rely on the CT data solely as it is difficult to relate the RF information to its CT counterpart. This paper describes the development of a graphical user interface application to co-register the CT images and the information from the RF generator temporally. Information from the RF generator, CT images during the RFA, and the pre-RFA CT images are displayed together. Users pinpoint a specific timestamp based on the RFA operation, and the corresponding CT images are retrieved and displayed.

\begin{tabular}{|c|c|}
\hline Author & $\begin{array}{l}\text { - } \text { Mah, Y. H. } \\
\text { - } \quad \text { Abdullah, B. J. J. } \\
\text { - Ng, K. H. } \\
\text { - } \quad \text { Tan, L. K. } \\
\text { - Wong, J. H. D. }\end{array}$ \\
\hline Source & Journal of Mechanics in Medicine and Biology \\
\hline ISSN & $0219-5194$ \\
\hline $\mathrm{DOI}$ & $10.1142 / \mathrm{s} 0219519410003642$ \\
\hline Volume (Issue) & $10(4)$ \\
\hline Page & $675-681$ \\
\hline Year & 2010 \\
\hline
\end{tabular}

Keyword:

Computed tomography, DICOM, minimal-invasive therapy, radiofrequency, ablation, temporal registration, lung-cancer, carcinoma

Please Cite As:

MAH, Y. H., ABDULLAH, B. J. J., NG, K. H., TAN, L. K. \& WONG, J. H. D. 2010. TEMPORAL REGISTRATION OF RADIOFREQUENCY INFORMATION AND CT IMAGES FOR RADIOFREQUENCY ABLATION PROCEDURE. Journal of Mechanics in Medicine and Biology, 10, 675-681. 
URL:

- $\quad$ http://apps.webofknowledge.com search via Accession No >> 000288221400009

- $\quad$ http://www.scopus.com/inward/record.url?eid=2-s2.079952607081\&partnerlD=40\&md5=f4861 ef558539bc5768dc15b310d3804

- $\quad$ http://www.worldscientific.com/doi/abs/10.1142/S0219519410003642 